\title{
Effects of lower limb eccentric strength training on functional measurements in football players with cerebral palsy
}

\author{
Alonso Alarcón ${ }^{1}$, Matías Henríquez ${ }^{2}$ and Luis Peñailillo ${ }^{1, *}$ \\ Received: $9^{\text {th }}$ December 2019; Accepted: $24^{\text {th }}$ July 2020; Published: $26^{\text {th }}$ November 2020
}

\begin{abstract}
This study examined the effects of eccentric strength training on muscle function and functionality in football players with cerebral palsy (CP). Eight players $(M=21.6, S D=5.9$ years) performed bilateral lower limb (LL) eccentric strength training for six-week at $80 \%$ of one repetition maximum (ECC), three times per week, while nine players ( $M=20.9, S D=6.6$ years) were used as controls (CTL). Knee extensor muscles isometric (MVC) strength, asymmetry between LL, thigh perimeter, balance (Y-balance test) and agility (Illinois agility test) were measured in both LL before and after training. CTL maintained all dependent variables unchanged after six weeks. MVC strength increased in the right $(M=22.7, S D=9.6 \%$; $\mathrm{p}<0.001 ; \mathrm{ES}=1.12)$ and in the left LL $(M=23.7, S D=7.6 \% ; \mathrm{p}<0.001 ; \mathrm{ES}=0.93)$ after ECC. Strength asymmetry decreased $(M=-22.7, S D=15.4 \% ; \mathrm{p}<0.001 ; \mathrm{ES}=0.58)$ after ECC. Thigh perimeter increased in the left $(M=4.8, S D=1.6 \%$; $<<0.001$; $\mathrm{ES}=0.84)$ and in the right $\mathrm{LL}(M=4.4, S D=1.5 \%$; $<<0.001 ; \mathrm{ES}=0.73)$ after $\mathrm{ECC}$. Balance improved in the left $(M=12.9, S D=3.2 \%$; $<<0.001 ; \mathrm{ES}=0.84)$ and in the right LL $(M=10.5, S D=4.5 \% ; \mathrm{p}<0.001 ; \mathrm{ES}=0.63)$ after ECC. The results suggest that eccentric strength training seems to effectively increase muscle strength, balance, and thigh perimeter and decrease strength asymmetry in football players with CP.
\end{abstract}

Keywords: Exercise training; brain injury; soccer; Y-balance test; agility

\section{Introduction}

Cerebral palsy (CP) is defined as movements and posture disorders produced by an injury sustained in an immature central nervous system (Jones, Morgan, Shelton, \& Thorogood, 2007). CP is a non-progressive condition and the cerebral injury is produced before the first 5 years of life (Carroll, Leiser, \& Paisley, 2006). The physical characteristics of CP include lower voluntary motor control, spasticity, muscular weakness, limited range of movement, and lower aerobic capacity to name a few (Jeng et al., 2013; Scholtes et al., 2012). The muscular weakness has been attributed to incomplete muscular recruitment, the lower discharge ratio of motor units, inappropriate muscular co-activation, secondary myopathy and changes in muscular physiology (Ito et al., 1996; Rose \& Mcgill, 1998). Furthermore, structural muscle differences in people with CP include decreased muscle volume and fiber length, increased intramuscular fat and length of Achilles tendon when compared to able-bodied people (Gillett, Boyd, Carty, \& Barber, 2016; Rose \& Mcgill, 1998). These changes typically induce lower aerobic and anaerobic capacity, also, the lower range of motion may affect the balance and mobility (Jeng et al., 2013). This could affect the quality of life, but also decrease the physical performance of individuals with $\mathrm{CP}$ that play sports 
(Carroll et al., 2006; Dallmeijer et al., 2017; Jeng et al., 2013; Ross, MacDonald, \& Bigouette, 2016).

Historically, strength training in spastic muscles was contraindicated based in the speculation that strength training could induce an increase in muscular tone, affecting even more the motor control and postural alignment (Park \& Kim, 2014; Scholtes et al., 2008; Steenbergen \& van der Kamp, 2008). Nevertheless, it has recently been shown that strength training has no contraindication in spastic muscles, and conversely, it has positive effects in muscle strength, without affecting the muscular tone (Park \& Kim, 2014; Scholtes et al., 2008). Furthermore, muscle strength has shown to be a good predictor of gross motor function and independent ambulation capacity in people with CP (Ross et al., 2016). Isometric training has shown to induce small muscle strength improvements without associated improvements in velocity and performance of determined quality motor movements (Dallmeijer et al., 2017; Gillett et al., 2016). Concentric strength training has shown to improve dimensions D (Biped), and E (Walk, Run and Jump) of the Gross Motor Function Measure (Ross et al., 2016; Scholtes et al., 2012, 2008). Moreover, McNee et al. (2009) showed 23\% increase in muscle volume in the medial and lateral gastrocnemius after 10 weeks of resistance training in children's with CP (Mcnee, Gough, Morrisey, \& Shortland, 2009). Additionally, it has also been shown that strength training including a functional circuit and home-based training induced improvements in balance, agility and mobility, without improvement in gait speed in participants with CP (Jeng et al., 2013; Koldoff \& Holtzclaw, 2015; Ross et al., 2016; Scholtes et al., 2012). Thus, it seems that resistance training is beneficial for patients with $\mathrm{CP}$.

For instance, six weeks of progressive eccentric strength training for upper limb showed to induce higher torque production and increases in neural efficiency during voluntary muscular contraction in individuals with CP (Reid, Hamer, Alderson, \& Lloyd, 2010). Interestingly, the increase in torque and the decrease in neural activation after eccentric training suggest a decrease in co-contraction, which is the main consequence of $\mathrm{CP}$, which decreases force production in people with CP (Reid et al., 2010). The authors declared that a workload close to $50 \%$ of the maximal eccentric contraction used during the training sessions was not enough to produce greater muscle adaptations (Reid et al., 2010). Thus, it is possible that a greater workload is necessary to induce greater muscle adaptations in people with CP. Furthermore, it has been shown that concentric and eccentric training induce increases in fascicle pennation angle and muscle fascicle length, which may be related to the morphological and architectonic adaptations shown in children and adolescents with CP (Gillett et al., 2016; Reid et al., 2010). Therefore, the eccentric strength training seems to be a useful and viable tool, but scarcely used and little explored in people with CP. Football 7-a-side is a popular sport practiced among people with CP. This discipline has similar physical, technical and tactical demands compared to able-bodied players (Yanci, Castillo, Iturricastillo, Urbán, \& Reina, 2018).

Football players with CP exhibit specific motor impairments, which may affect physical performance and football skills (Reina, Iturricastillo, Castillo, Urbán, \& Yanci, 2020). The physical demands required during football 7 -a-side of CP players include high-intensity actions, acceleration/decelerations, sprints and changes of direction, which are performed within specific compromises such as the lower aerobic/anaerobic capacity, spasticity, cocontraction, impaired coordination and balance problems presented in CP (Kloyiam, Breen, Jakeman, Conway, \& Hutzler, 2011; Reina et al., 2020; Yanci et al., 2016; Yanci, Castillo, Iturricastillo, \& Reina, 2019). Thus, CP football players may benefit of physical training in order to optimize physical performance in football.

Eccentric muscle actions constantly occur during motor activities, especially during breaking actions and deceleration of the body, which are necessary for high-intensity 
activities during football (de Hoyo et al., 2016). Eccentric strength training could be a good alternative to improve physical performance in football players with $\mathrm{CP}$, as they have a compromised neuromuscular capacity and muscle imbalances, but still need to perform deceleration actions and changes of direction with a high demand of eccentric strength (Reina, Elvira, Valverde, Roldán, \& Yanci, 2019; Reina, Sarabia, Caballero, \& Yanci, 2017). For instance, strength training have shown positive effects in football players without disability such as increases in running speed, jump ability and reduced injury risk (Silva, Nassis, \& Rebelo, 2015), also this type of training has shown to be superior to conventional strength training at improving muscle strength, muscle mass (Hortobagyi et al., 1996) and induce greater cortical activity (Fang, Siemionow, Sahgal, Xiong, \& Yue, 2001; Roig et al., 2009) than conventional or concentric training. Thus, eccentric strength training could be an alternative to improve motor function in $\mathrm{CP}$ football players. However, these effects have not been reported in football players with $\mathrm{CP}$.

Therefore, the aim of this study was to determine the effects of lower limb eccentric training in the muscular strength and functional motor parameters in football players with CP. We hypothesized that the eccentric training will increase the knee extensor strength, which would induce decrease the strength asymmetry of knee extensor and improve the unipodal balance of football players with CP.

\section{Materials and Methods}

\section{Participants}

Seventeen male football players of the Chilean Paralympic 7-a-Side football team participated in this study. The participants have a sport classification and were randomly assigned in two groups, nine subjects participated in the control group (CTL) and eight in the eccentric strength training group (ECC). This study was carried out during the preparation for a tournament. The physical characteristics of the participants are presented in table 1, the sport classes and description of physical impairments of participants are described in table 2. Players were notified of the research design and signed an informed consent approved by the institutional ethics committee of the university and the study was conducted according to the Helsinki declaration (Resolution $\mathrm{n}^{\circ}$ 2017-054).

Table 1. Mean physical characteristics of the participants and Student's t-test between groups.

\begin{tabular}{cccc}
\hline & CTL mean $(\mathrm{SD})$ & ECC mean $(\mathrm{SD})$ & p-value \\
\hline Age (years) & $20.9(6.6)$ & $21.6(5.9)$ & 0.81 \\
Height $(\mathrm{cm})$ & $169.0(6.0)$ & $170.0(5.0)$ & 0.61 \\
Body Mass $(\mathrm{kg})$ & $63.2(8.9)$ & $65.4(9.0)$ & 0.63 \\
Length right LL $(\mathrm{cm})$ & $92.7(3.2)$ & $94.3(3.2)$ & 0.33 \\
Length left LL $(\mathrm{cm})$ & $92.3(3.3)$ & $93.5(3.3)$ & 0.48 \\
\hline
\end{tabular}

CTL: Control group; ECC: eccentric strength training group; SD: standard deviation; cm: centimetre; kg: kilogram

Table 2. Sport classes and description of physical impairments of the participants

\begin{tabular}{cccc}
\hline Sport classes & Impairment description & Control group & Eccentric strength group \\
\hline FT5 & Bilateral spasticity & 2 & 2 \\
FT6 & Coordination impairment & 0 & 1 \\
FT7 & Unilateral spasticity & 6 & 4 \\
FT8 & Minimum impairment criteria & 1 & 1 \\
\hline
\end{tabular}




\section{Procedures}

Participants were invited to the laboratory to assess maximal voluntary isometric knee extensors strength of both limbs, balance using the $\mathrm{Y}$ balance test and agility using the modified Illinois agility test. All measures were complete before and $72 \mathrm{~h}$ after completion of the training period. All measurements were assessed in similar laboratory conditions.

\section{Measurements}

\section{Maximum isometric knee extensor muscular strength}

Maximum voluntary contraction (MVC) knee extensor strength was measured in a $45^{\circ}$ leg press machine customized with a force plate (Globus, Italy). The participants were in a seated position with butt and lumbar zone support. The knee and hip articulations were at $90^{\circ}$ of flexion. Three attempts were allowed in each lower limb (LL) consecutively in which muscle contraction was sustained for 4 seconds and 3 minutes of rest between attempts was allowed. Before the measurements, three submaximal contractions of familiarization were performed in which smooth muscle contraction was requested. The participants were encouraged to generate a maximum effort and the highest force value was considered for statistical analyses in newtons $(\mathrm{N})$. The effect of the eccentric strength training was based on the measure of MVC before and after the intervention in each LL (right and left) and as the average of both LL. Furthermore, the strength asymmetry was considered as the differences in the dominant LL versus non-dominant LL and was shown as percentage difference between legs (\%).

\section{Balance}

The balance was assessed using the Y-balance test, according to a previous study (Linek, Sikora, Wolny, \& Saulicz, 2017). The test was performed while the participant is standing on one leg and were asked to move a pointer as far as possible in three different points at distances (anterior, posterolateral and posteromedial) with the contralateral leg in three consecutive attempts. The distance reached was considered for each leg and always started moving the pointer with the dominant leg. Three attempts of familiarization with the test with each leg were allowed before the assessment. A valid attempt was when the subject managed to move the distance marker in a controlled manner, without kicking and returned to the initial position without the support of the foot that was in swing fully controlling the movement. The distance was expressed in centimeters and the last punctuation was expressed through the composite range distance index, where this formula considers the mean of the sum of the three best attempts with one leg and the triple distance of the leg analyzed (Linek et al., 2017).

\section{Agility}

The modified Illinois agility test consisted of performing a sprint through a circuit with a delimited distance of 5 meters of width and 5 meters long in the shortest time possible (Rouissi, Chtara, Berriri, Owen, \& Chamari, 2016). In the middle zone, three cones were separated by 2.5 meters. The starting position was with the participant in the prone position with both hands at the height of shoulders, at the started sign, the participant should stand up as soon as possible and perform the circuit from left to right in the shortest time possible. The time was measured by separated assessors with a digital chronometer (Timex ironman $\mathrm{T} 5 \mathrm{~K} 790$ ), and participants were instructed not to throw away any cone. Three attempts were performed with 3 minutes of rest between repetitions. The best attempt was considered for statistical analysis. 


\section{One repetition maximum strength}

Before training one repetition maximum (1RM) strength was assessed in a leg press machine (R2 sport, USA). The unilateral extension 1RM was measured in the dominant and non-dominant leg. Before the testing a standardized warm-up was performed, in which the participants performed six repetitions with a low load ( $<30 \%$ self-perception $1 R M)$, then three repetitions with a heavier load $(\sim 50 \%$ of self-perceived $1 R M)$ and finally the $1 R M$ testing started with a series of isolated repetitions with incremental loads. The 1RM test was recorded as the maximum weight that could be lifted for the entire range of movement using the correct technique, all this with the consideration of the motor disability profile, limited range of movement in LL and muscle force production impairment of each player. If the weight was lifted with adequate technique, it was increased by $0.5-2.3 \mathrm{~kg}$, and the players attempted the next repetition following the protocol used by a previous study (Peñailillo, Espíldora, Jannas-Vela, Mujika, \& Zbinden-Foncea, 2016). All the participants were supervised for the correct execution form, and verbal encouragement was given.

\section{Eccentric strength training}

The eccentric strength training of both lower limbs was performed on a $45^{\circ}$ leg press machine for 6 weeks, 3 times per week in no consecutive days. Participants performed 4 sets of 8 repetitions at $80 \%$ of 1 repetition maximum with 3 minutes of recovery between sets. The individual workload was used according to the evaluation of the 1 repetition maximum in the affected and unaffected body side. For all the training sessions, the load was maintained during the 6-week period. Prior to the commencement of this study, we performed a pilot study in which it was determined that $80 \%$ of $1 \mathrm{RM}$ was well tolerated and safe by this population. The eccentric overloading was achieved performing the concentric phase of the movement (i.e. lifting) with both legs, while the eccentric phase (i.e. descending) was resisted with a single leg in 4 seconds. Both LL were trained separately, and the range of the movement performed was from a full knee extension $\left(180^{\circ} \mathrm{knee}\right.$ angle) to a $90^{\circ} \mathrm{knee}$ flexion in consideration of the individual physical impairments of players (Wirth, Keiner, Szilvas, Hartmann, \& Sander, 2015). All the training sessions were supervised by one of the researchers who encouraged the participants to resist the load during the eccentric phase and assisted in the concentric phase. All participants completed the training and referred no difficulties during training.

\section{Statistical analysis}

The statistical analysis was performed in GraphPad Prism version 6.oe. The distribution of each variable was verified by the Shapiro-Wilk normality test, from which all variables resulted normally distributed. To compare the changes in time (pre and post) between both groups (ECC and CTL) a two-way analysis of variance (ANOVA) was performed. In addition, to compare changes for the knee extensor muscular strength, strength asymmetry (left versus right leg), balance, tight perimeter and agility between CTL and ECC an independent Student's t-test was performed. The effect size was calculated for each treatment to determine the magnitude of change in the outcome variable using the mean difference, pooled pre and post-test standard deviation and pre- and post-test sample size pairs. Values were interpreted as $0.0<$ trivial $<0.2,0.2 \leq$ small $<0.6$, $0.6 \leq$ moderate $<1.2,1.2 \leq$ large $<$ 2.0, 2.0 $\leq$ very large < 4.0 (Hopkins, Marshall, Batterham, \& Hanin, 2009). The level of significance was set at $\mathrm{p}<0.05$. In addition, 95\% confidence interval (95\%CI) are presented for mean comparisons. The results are shown as means $(M)$ and standard deviations $(S D)$. 


\section{Results}

\section{Maximum voluntary contraction strength}

The two-way ANOVA interaction effect for the right $(\mathrm{p}=0.37)$, left $(\mathrm{p}=0.91)$ legs or bilateral $(\mathrm{p}=0.35)$ after training was not statistically significant. Both groups were similar at baseline in the right (CTL: $M=1070.8, S D=320.4 \mathrm{~N}$ and ECC: $M=1235.0, S D=475.3 \mathrm{~N}$ ), left (CTL: $M=817.2, S D=111.3 \mathrm{~N}$ and ECC: $M=1213.3, S D=317.0 \mathrm{~N}$ ) and bilateral LL (CTL: $M=944.0, S D=159.6 \mathrm{~N}$ and ECC: $M=1224.6, S D=340.3 \mathrm{~N})$. However, greater changes in MVC strength were observed in the right (ECC: $M=22.7, S D=9.6 \% ; \mathrm{p}<0.001 ; \mathrm{ES}=1.12$; 95\%CI=-8.07-3.68) and left LL (CTL: $M=-0.7, S D=2.7 \%$ and ECC: $M=23.7, S D=7.6 \%$; $\mathrm{p}<0.001 ; \mathrm{ES}=0.93 ; 95 \% \mathrm{CI}=-6.46-2.81)$ after ECC compared to CTL. Bilateral MVC strength increased after $\mathrm{ECC}(M=25.4, S D=23.5 \%$; $<<0.001 ; \mathrm{ES}=0.55 ; 95 \% \mathrm{CI}=-2.63-0.46)$ compared to CTL ( $M=-0.5, S D=2.4 \%)$ as shown in Figure 1.
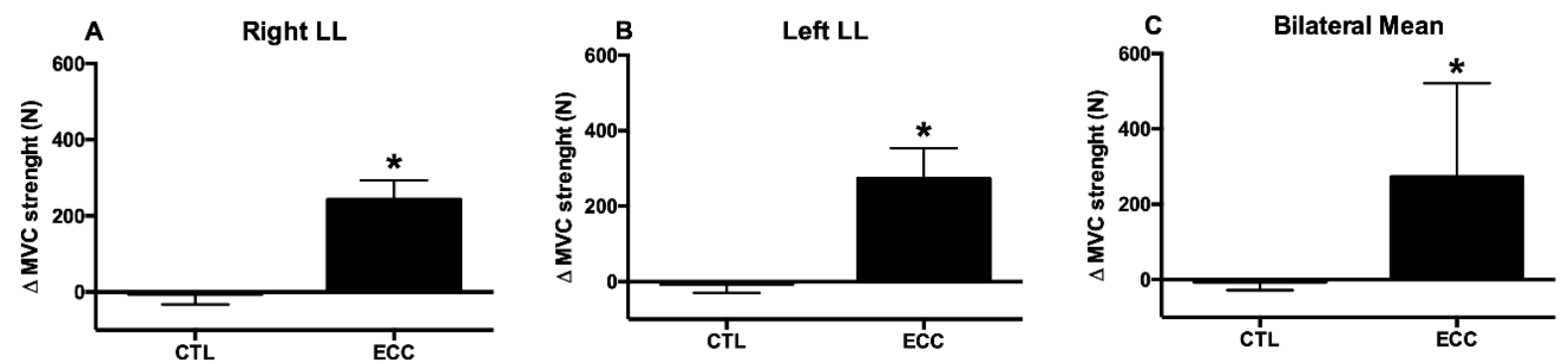

Figure 1. Comparison of the changes (Post-Pre) in maximum muscular strength after training in Newtons (N) between CTL and ECC (A). $\Delta$ Maximum strength right LL, (B). $\Delta$ Maximum strength left LL, and (C). $\Delta$ Mean bilateral maximum strength. Results are shown as mean (SD)Strength Asymmetry

The two-way ANOVA interaction effect for asymmetry $(\mathrm{p}=0.81)$ after training was not statistically significant. Both groups were at similar levels of asymmetry at baseline (CTL: $M=21.8, S D=20.0 \%$ and ECC: $M=20.1, S D=20.9 \%)$. However, the ECC decreased strength asymmetry ( $M=-22.7, S D=15.4 \% ; \mathrm{p}<0.001 ; \mathrm{ES}=0.58 ; 95 \% \mathrm{CI}=0.73-3.02)$, while CTL remained unchanged $(M=10.7, S D=19.5 \%$; Figure 2).

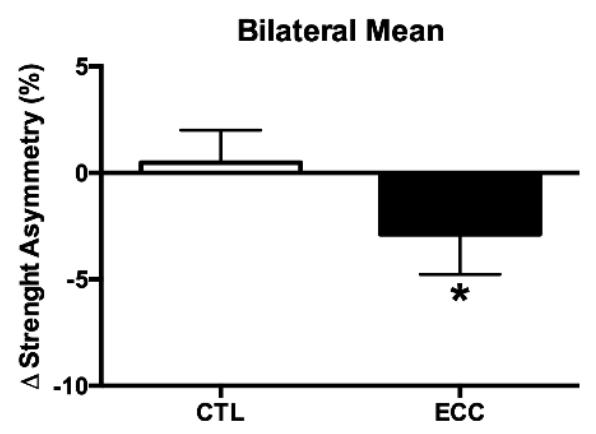

Figure 2. Comparison of the changes (Post-Pre) in muscular strength asymmetry after training (\%) between CTL and ECC. $\Delta$ Strength asymmetry between Lower Limbs (\% of change LL dominant versus LL non-dominant). ${ }^{*} \mathrm{p}<0.05$. Results are shown as mean (SD)

\section{Balance}

The two-way ANOVA interaction effect for all balance measures after training was not statistically significant. Balance measures were similar in the right (CTL: $M=76.4, S D=24.8$ $\mathrm{cm}$ and ECC: $M=69.5, S D=14.7 \mathrm{~cm}$ ), left (CTL: $M=72.9, S D=26.0 \mathrm{~cm}$ and ECC: $M=71.1$, $S D=14.4 \mathrm{~cm}$ ) and bilateral LL (CTL: $M=74.7, S D=24.2 \mathrm{~cm}$ and ECC: $M=70.3, S D=9.1 \mathrm{~cm}$ ). The ECC group improved the right LL (CTL: $M=0.7, S D=3.3 \%$ and ECC: $M=10.5, S D=4.5 \%$; 
p<0.001; ES=0.63; 95\%CI=-3.59-1.11), left LL (CTL: $M=0.2, S D=2.5 \%$ and ECC: $M=12.9$, $S D=3.2 \% ; \mathrm{p}<0.001 ; \mathrm{ES}=0.84 ; 95 \% \mathrm{CI}=-5.68-2.37$ ) and bilateral balance (CTL: $M=0.6$, $S D=1.4 \%$ and ECC: $M=12.2, S D=13.3 \% ; \mathrm{p}<0.001 ; \mathrm{ES}=0.53 ; 95 \% \mathrm{CI}=-2.30-0.22)$, while CTL remained unchanged (Figure 3 ).
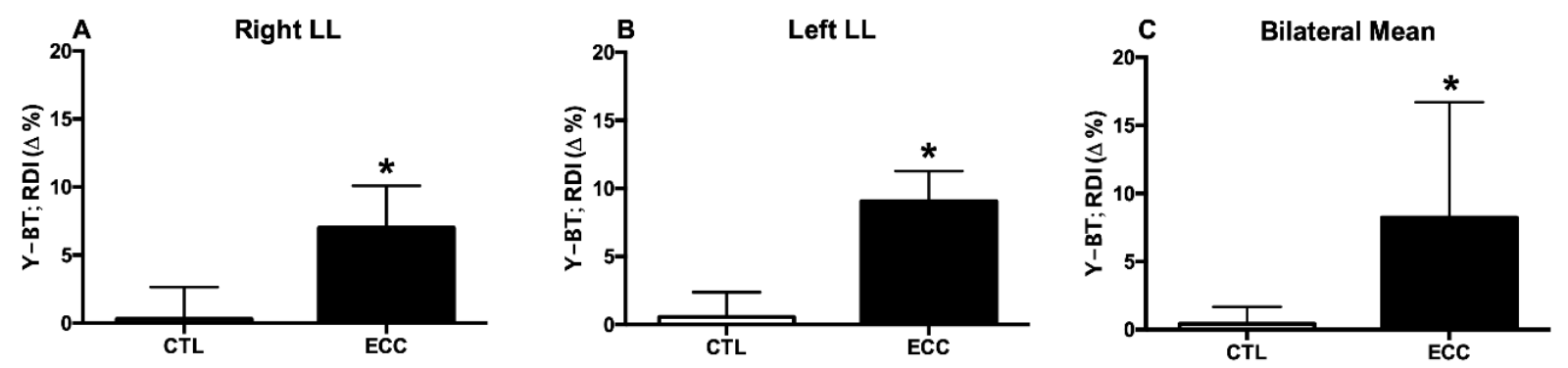

Figure 3. Comparison of the changes (Post-Pre) in Balance (Y-BT), expressed as range distance index $(\Delta \mathrm{RDI} \%)$ after training between CTL and ECC group. (A). $\Delta \%$ RDI right LL, (B). $\Delta \%$ RDI left LL and (C). $\Delta \%$ RDI bilateral average. ${ }^{*} \mathrm{p}<0.05$. Results are shown as mean (SD)

\section{Thigh perimeter}

The two-way ANOVA interaction effect for thigh perimeter $(\mathrm{p}=0.23)$ after training was not statistically significant. The baseline thigh perimeters were similar for right (CTL: $M=48.2, S D=1.5 \mathrm{~cm}$ and ECC: $M=47.6, S D=3.9 \mathrm{~cm}$ ) and left LL (CTL: $M=47.4, S D=1.7 \mathrm{~cm}$ and ECC: $M=46.6, S D=3.1 \mathrm{~cm}$ ). Thigh perimeter increased in the right LL (CTL: $M=0.5$, $S D=0.9 \%$ and ECC: $M=4.4, S D=1.5 \% ; \mathrm{p}<0.001 ; \mathrm{ES}=0.73 ; 95 \% \mathrm{CI}=-4.60-1.74)$ and the left thigh perimeter after ECC (CTL: $M=0.2, S D=0.5 \%$ and ECC: $M=4.8, S D=1.6 \%$; $<0.001$; $\mathrm{ES}=0.84 ; 95 \% \mathrm{CI}=-5.65-2.36$ ), and remained unchanged in CTL (Figure 4).
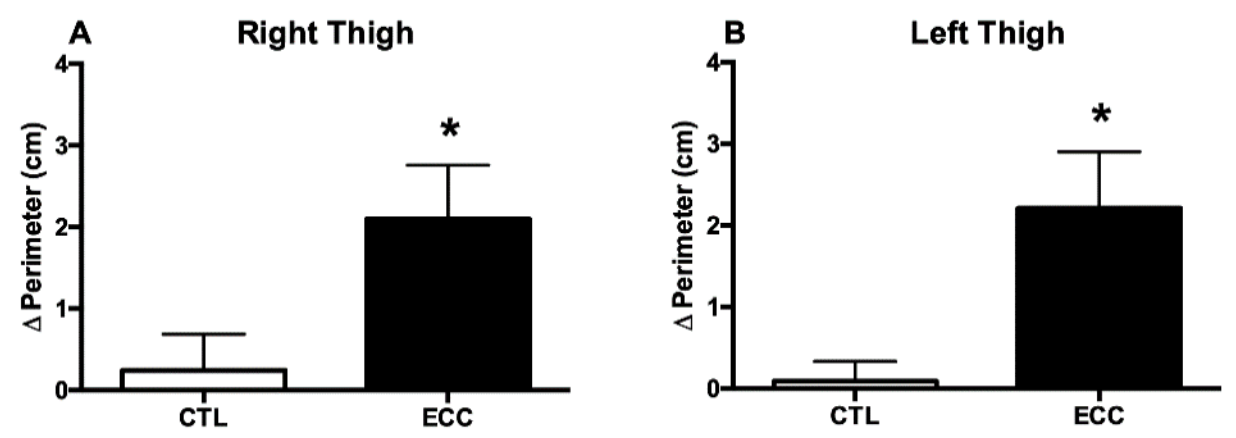

Figure 4. Comparison of the changes (Post-Pre) in thigh perimeter measurements between both lower limbs (cm) after training between CTL and ECC. Right thigh perimeter and Left thigh perimeter. ${ }^{*} \mathrm{p}$ $<0.05$. Results are shown as mean (SD)

\section{Agility}

The two-way ANOVA interaction effect of agility $(\mathrm{p}=0.95)$ after training was not statistically significant. Baseline values of the Illinois agility test were similar before training (CTL: $M=13.8, S D=1.6 \mathrm{~s}$ and ECC: $M=13.6, S D=1.3 \mathrm{~s}$ ). The changes in the Illinois agility test were similar between CTL $(M=0.1, S D=2.8 \% ; \mathrm{p}=0.47 ; \mathrm{ES}=0.47 ; 95 \% \mathrm{CI}=-0.94-0.91)$ and $\mathrm{ECC}(M=0.3, S D=4.8 \% ; \mathrm{p}=0.44 ; \mathrm{ES}=0.50 ; 95 \% \mathrm{CI}=-0.94-1.02)$ after training.

\section{Discussion}

The aim of this study was to determine the effects of eccentric strength training on muscular strength and motor function parameters in football players with CP. The results of this study show that the eccentric strength training group (ECC) achieved greater increases in knee extensor maximal strength, decreased strength asymmetry, increased thigh 
perimeter, and improved balance when compared to a control group (CTL). These results are important since limited information exists about the gains of muscle strength and its relationship with the improvements of balance and agility in elite athletes with $\mathrm{CP}$ (Dallmeijer et al., 2017; García et al., 2016; Kobal et al., 2017; Park \& Kim, 2014; Ross et al., 2016).

It seems that the implementation of an eccentric strength training program for athletes with CP improved motor function. These results are in concordance with other studies in which strength training showed similar improvements in children and adolescents with CP (Gillett et al., 2016; Park \& Kim, 2014; Reid et al., 2010). For instance, six weeks of eccentric strength training resulted in $25 \%$ improvements in peak torque and $42 \%$ torque production in the range of movement in children and adolescents with CP (Reid et al., 2010). However, our knee extensor MVC strength gains showed to be lower compared to a study of six weeks at supramaximal training intensity (151-214\%) in able-bodied participants (+28.2\%; Wirth et al., 2015). Thus, it is possible that neuromuscular impairments of individuals with CP could have reduced the gains of muscle strength induced by eccentric training in the present study. The damage of the descending pathways due to the brain injury causes paresis with a reduction of the voluntary contraction and recruitment of motor units, which induce structural muscle abnormalities, reduced muscle size, abnormal muscle composition and altered neural control (Verschuren et al., 2018). This could contribute to the reduced muscle strength and muscle gains possibilities in people with CP compared to adults with typically developing (Verschuren et al., 2018). This needs further investigation.

It is possible that improvements in neuromuscular coordination between agonists and antagonist muscles and decreasing the magnitude of the co-contraction showed in previous studies are also related to the improvements observed in muscle strength in our study (Reid et al., 2010). The reduction in muscle strength asymmetry found could be attributed to the cross-training effect of eccentric strength training. Cross-training effects have been shown to induce some neuromuscular adaptations in the limbs immobilized or non-trained when the contralateral limb is been trained (Weir, Housh, Housh, \& Weir, 1995). However, this has not been studied in spastic muscles. These effects could be relevant when looking improvements in spastic lower limbs and training the non-spastic limb may induce some improvements in the spastic side (Hussain, Onambele, Williams, \& Morse, 2014). The important strength improvements described in this study may be due to the greater increase in fascicle length and the addition of sarcomeres in series (Franchi, Reeves, \& Narici, 2017). This is important since people with CP showed lengthened sarcomeres and shortened muscles in affected muscles contributing to weakness and low active force characteristics in this population (Graham et al., 2016). Thus, eccentric exercise could have additional architectonical benefits for people with $\mathrm{CP}$, highlighting the importance of improving strength in populations with disabilities (Feter, Calonego, Cavanhi, \& del Vecchio, 2018).

In addition, the eccentric muscle contraction is present in different skills necessary for sprinting, jumping, change of direction, dribbling, passing and kicking. This type of training could have a positive influence taking into account the particularities of the sport classification for each player (Miyamoto, Maehana, \& Yanagiya, 2019; Pastor, CampayoPiernas, Pastor, \& Reina, 2019). Also, the described strength gains and decreased asymmetry could have practical implications for the training process on CP football players related to the improvements in motor actions and football skills (Reina et al., 2019; Yanci et al., 2016).

It is important to consider that the adaptations of the eccentric strength training observed in this study were obtained without adjusts in the workload since training intensity was maintained at $80 \%$ of 1 repetition maximum. Ross et al. (2016) and Reid et al. (2010) described that a progressive load increases (i.e. $5 \%$ of 1 repetition maximum weekly) could be appropriated to maximize strength gains from strength training. In fact, their workload 
regime resulted in increments of $25 \%$ of torque and $42 \%$ of work in the eccentric phase, which reached similar levels compared to people without disability (Reid et al., 2010; Ross et al., 2016). Unfortunately, we did not adjust the workload weekly, this could explain the slightly lower strength gains found compared to other studies.

We did not find changes in the agility test. However, Jen et al. reported that muscular strength increased after strength training, which was accompanied by improvements in the agility performance test (Jeng et al., 2013). Nevertheless, Jeng et al. (2013) used the 10-m shuttle run test, thus it is possible that the agility test used in the present study (i.e. modified Illinois test) was not sensitive enough to detect changes in this population. Furthermore, in Jeng et al. (2013) study different exercises were prescribed, and self-loading training instead overload training was used. It is also possible that the lack of change in agility performance was due to the type of training performed in the current study since speed and workload were lower compared to previous studies, which was insufficient to improve agility in CP football players (Jeng et al., 2013; Linek et al., 2017; Reina et al., 2017; Rouissi et al., 2016). De Hoyo et al. (2016) reported benefits after a 10-week concentric-eccentric training reporting improvements in the change of direction of able-bodied football players (de Hoyo et al., 2016). Moreover, Jones et al. (2009) showed an important relationship between the capacity of change of direction, components of agility and maximal eccentric strength in the lower limbs. Noteworthy, football players with CP showed a lower capacity to perform activities related to turn, change of direction and acceleration/deceleration at high intensity possibly due to the physical impairment from spasticity (Reina et al., 2017; Yanci et al., 2019). Thus, it seems that eccentric training does not improve agility due to the specificity of the training or due to a poor specificity of the test assessed in this study. More research is necessary to test the agility in this population with more direct/specific tests. It seems that ECC training improved balance performance, which is an important skill for CP athletes. However, more research regarding the assessment and implementation of other balance training modalities is warranted (Van Biesen \& Pineda, 2019; Macdougall, O'Halloran, Sherry, \& Shields, 2019).

Future studies should establish the effect of long-term training ( $>6$ weeks), specifically in the maintenance of the maximal strength gains and balance. This may prolong the functional level and prevent premature motor deterioration in people with CP. This study is not free of limitations. For instance, we acknowledge that our sample size is rather small, however we had access to a limited number of participants due to this group of players were the national team of football 7-a side and few players were available at this level. Furthermore, due to the specific training period of the team (i.e. preparing for a tournament) it was not possible to adjust workload during the training period. In addition, the analysis of specific variables such as acceleration/deceleration, jump capacity, sprint and load during a game or other more football performance measures before and after the training protocol were not examined. Further research is warranted in this area and studies should examine the sports-specific transferences of muscle function improvements found in the present study.

In conclusion, eccentric strength training increased muscle strength, improved unipodal balance, increased muscular perimeter and decreased strength asymmetry in football players with CP. However, this type of training seems to be not effective to improve agility in these individuals. This type of training can be useful for the development of a good muscular strength foundation in these athletes. Thus, eccentric strength training can be safely prescribed to athletes with CP seeking for decreasing muscle strength asymmetries and imbalances.

\section{Perspectives}


Eccentric strength training in football players with $\mathrm{CP}$ is useful for gains of muscle strength and balance in lower limbs. Eccentric training is feasible at a high workload, which induced improvements in motor performance in football players with CP. These results provide novel information about strength training in football players with $\mathrm{CP}$, and coaches should introduce this modality of training to increase athletic performance. This study extends the body of knowledge regarding sports performance and adapted physical activity disciplines (Gamonales, Muñoz-Jiménez, León-Guzmán, \& Ibáñez, 2018). It would be interesting for future studies to analyze the metabolic and structural adaptations of the eccentric strength training in the spastic muscle of athletes with CP.

Author affiliations:

1 Exercise Science Laboratory, School of Kinesiology, Faculty of Medicine, Universidad Finis Terrae, Santiago, Chile; a.alarcon.elgueta@gmail.com / lpenailillo@uft.cl

2 Department of Adapted physical Activity, National Rehabilitation Centre Pedro Aguirre Cerda, Santiago, Chile; matias.henriquez@inrpac.cl

* Correspondence: lpenailillo@uft.cl; Tel.: +569-9319-8108

Author Contributions: Conceptualization, A.A. and L.P.; Methodology, A.A.; Formal Analysis, L.P.; and MH Writing-Original Draft Preparation, M.H., L.P. and A.A.; Writing-Review \& Editing, M.H., L.P. and A.A

Funding: This research received no external funding.

Conflicts of Interest: The authors declare no conflict of interest.

\section{References}

Carroll, K. L., Leiser, J., \& Paisley, T. S. (2006). Cerebral Palsy: physical activity and sport. Current Sports Medicine Reports, 5(6), 319-322. https://doi.org/10.1097/o1.CSMR.0000306437.21359.f7

Dallmeijer, A. J., Rameckers, E. A., Houdijk, H., de Groot, S., Scholtes, V. A., \& Becher, J. G. (2017). Isometric muscle strength and mobility capacity in children with cerebral palsy. Disability and Rehabilitation, 39(2), 135-142. https://doi.org/10.3109/09638288.2015.1095950

de Hoyo, M., Sañudo, B., Carrasco, L., Mateo-Cortes, J., Domínguez-Cobo, S., Fernandes, O., Del Ojo, J. J. \& Gonzalo-Skok, O. (2016). Effects of 10-week eccentric overload training on kinetic parameters during change of direction in football players. Journal of Sports Sciences, 34(14), 1380-1387. https://doi.org/10.1080/02640414.2016.1157624

Fang, Y., Siemionow, V., Sahgal, V., Xiong, F., \& Yue, G. H. (2001). Greater movementrelated cortical potential during human eccentric versus concentric muscle contractions. Journal of Neurophysiology, 86(4), 1764-1772. https://doi.org/10.1152/jn.2001.86.4.1764

Feter, N., Calonego, C., Cavanhi, A. C., \& del Vecchio, F. B. (2018). Wheelchair basketball: Fitness and quality of life. European Journal of Adapted Physical Activity, 11(1), 1-11. https://doi.org/10.5507/EUJ.2018.001

Franchi, M. V., Reeves, N. D., \& Narici, M. V. (2017). Skeletal muscle remodeling in response to eccentric vs. concentric loading: morphological, molecular, and metabolic adaptations. Frontiers in Physiology, 8, 1-16. https://doi.org/10.3389/fphys.2017.00447

Gamonales, J. M., Muñoz-Jiménez, J., León-Guzmán, K., \& Ibáñez, S. J. (2018). 5-A-side football for individuals with visual impairments: A review of the literature. European Journal of Adapted Physical Activity, 11(1). https://doi.org/10.5507/EUJ.2018.004

García, C. C., Alcocer-Gamboa, A., Ruiz, M. P., Caballero, I. M., Faigenbaum, A. D., EsteveLanao, J., Saiz, B., Lorenzo, T., Lara, S. L. (2016). Metabolic, cardiorespiratory, and neuromuscular fitness performance in children with cerebral palsy: A comparison with healthy youth. Journal of Exercise Rehabilitation, 12(2), 124-131. https://doi.org/10.12965/jer.1632552.276

Gillett, J. G., Boyd, R. N., Carty, C. P., \& Barber, L. A. (2016). The impact of strength training on skeletal muscle morphology and architecture in children and adolescents 
with spastic cerebral palsy: A systematic review. Research in Developmental Disabilities, 56, 183-196. https://doi.org/10.1016/j.ridd.2016.06.003

Graham, H. K., Rosenbaum, P., Paneth, N., Dan, B., Lin, J.-P., Damiano, D. L., Becher, J. G., Gaebler-Spira, D., Colver, A., Reddihough, D. S., Crompton, K. E., Lieber, R. L. (2016). Cerebral palsy. Nature Reviews Disease Primers, 2, 15082. https://doi.org/10.1038/nrdp.2015.82

Hopkins, W. G., Marshall, S. W., Batterham, A. M., \& Hanin, J. (2009). Progressive statistics for studies in sports medicine and exercise science. Medicine and Science in Sports and Exercise, 41(1), 3-12. https://doi.org/10.1249/MSS.obo13e31818cb278

Hortobagyi, T., Hill, J. P., Houmard, J. A., Fraser, D. D., Lambert, N. J., \& Israel, R. G. (1996). Adaptive responses to muscle lengthening and shortening in humans. Journal of Applied Physiology, 8o(3), 765-772. https://doi.org/10.1152/jappl.1996.80.3.765

Hussain, A. W., Onambele, G. L., Williams, A. G., \& Morse, C. I. (2014). Muscle size, activation, and coactivation in adults with cerebral palsy. Muscle \& Nerve, 49(1), 7683. https://doi.org/10.1002/mus.23866

Ito, J., Araki, A., Tanaka, H., Tasaki, T., Cho, K., \& Yamazaki, R. (1996). Muscle histopathology in spastic cerebral palsy. Brain and Development, 18(4), 299-303. https://doi.org/10.1016/0387-7604(96)oooo6-X

Jeng, S. C., Yeh, K. K., Liu, W. Y., Huang, W. P., Chuang, Y. F., Wong, A. M., \& Lin, Y. H. (2013). A physical fitness follow-up in children with cerebral palsy receiving 12-week individualized exercise training. Research in Developmental Disabilities, 34(11), 40174024. https://doi.org/10.1016/j.ridd.2013.08.032

Jones, M., Morgan, E., Shelton, J. E., \& Thorogood, C. (2007). Cerebral Palsy: Introduction and Diagnosis (Part I). Journal of Pediatric Health Care, 21(3), 146-152. https://doi.org/10.1016/j.pedhc.2006.06.007

Jones, P., Bampouras, T., \& Marrin, K. (2009). An investigation into the physical determinants of change of direction speed. Journal of Sports Medicine and Physical Fitness, 49(1), 97-104.

Kloyiam, S., Breen, S., Jakeman, P., Conway, J., \& Hutzler, Y. (2011). Soccer-specific endurance and running economy in soccer players with cerebral palsy. Adapted Physical Activity Quarterly, 28(4), 354-367. https://doi.org/10.1123/apaq.28.4.354

Kobal, R., Loturco, I., Barroso, R., Gil, S., Cuniyochi, R. R., Ugrinowitsch, C., ... Tricoli, V. (2017). Effects of different combinations of strength, power, and plyometric training on the physical performance of elite young soccer players. Journal of Strength and Conditioning Research, 31(6), 1468-1476. https://doi.org/10.1519/JSC.0000000000001609

Koldoff, E. A., \& Holtzclaw, B. J. (2015). Physical activity among adolescents with cerebral palsy: An integrative review. Journal of Pediatric Nursing, 30(5), e105-e117. https://doi.org/10.1016/j.pedn.2015.05.027

Linek, P., Sikora, D., Wolny, T., \& Saulicz, E. (2017). Reliability and number of trials of Y Balance Test in adolescent athletes. Musculoskeletal Science and Practice, 31(7), 7275. https://doi.org/10.1016/j.msksp.2017.03.011

Macdougall, H., O'Halloran, P., Sherry, E., \& Shields, N. (2019). A pilot randomised controlled trial to enhance well-being and performance of athletes in para sports. European Journal of Adapted Physical Activity, 12(2), 1-19. https://doi.org/10.5507/euj.2019.006

Mcnee, A. E., Gough, M., Morrisey, M. C., \& Shortland, A. P. (2009). Increases in muscle volume after plantarflexor strength training in children with spastic cerebral palsy. Developmental Medicine \& Child Neurology, 51(6), 429-435. https://doi.org/10.1111/j.1469-8749.2008.03230.x

Miyamoto, A., Maehana, H., \& Yanagiya, T. (2019). The relationship between sprint speed and sprint motion in amputee soccer players. European Journal of Adapted Physical Activity, 12(2), 1-9. https://doi.org/10.5507/euj.2019.009

Park, E. Y., \& Kim, W. H. (2014). Meta-analysis of the effect of strengthening interventions in individuals with cerebral palsy. Research in Developmental Disabilities, 35(2), 239249. https://doi.org/10.1016/j.ridd.2013.10.021 
Pastor, D., Campayo-Piernas, M., Pastor, J. T., \& Reina, R. (2019). A mathematical model for decision-making in the classification of para-footballers with different severity of coordination impairments. Journal of Sports Sciences, 37(12), 1403-1410. https://doi.org/10.1080/02640414.2018.1560617

Peñailillo, L., Espíldora, F., Jannas-Vela, S., Mujika, I., \& Zbinden-Foncea, H. (2016). Muscle strength and speed performance in youth soccer players. Journal of Human Kinetics, 5O(1), 203-210. https://doi.org/10.1515/hukin-2015-0157

Reid, S., Hamer, P., Alderson, J., \& Lloyd, D. (2010). Neuromuscular adaptations to eccentric strength training in children and adolescents with cerebral palsy. Developmental Medicine and Child Neurology, 52(4), 358-363. https://doi.org/10.1111/j.1469-8749.2009.03409.x

Reina, R., Elvira, J., Valverde, M., Roldán, A., \& Yanci, J. (2019). Kinematic and kinetic analyses of the vertical jump with and without header as performed by para-footballers with cerebral palsy. Sports, 7(9), 209. https://doi.org/10.3390/sports7090209

Reina, R., Iturricastillo, A., Castillo, D., Urbán, T., \& Yanci, J. (2020). Activity limitation and match load in para-footballers with cerebral palsy: An approach for evidencebased classification. Scandinavian Journal of Medicine and Science in Sports, 30(3), 496-504. https://doi.org/10.1111/sms.13583

Reina, R., Sarabia, J. M., Caballero, C., \& Yanci, J. (2017). How does the ball influence the performance of change of direction and sprint tests in para-footballers with brain impairments? Implications for evidence-based classification in CP-Football. PLOS ONE, 12(11), e0187237. https://doi.org/10.1371/journal.pone.0187237

Roig, M., O’Brien, K., Kirk, G., Murray, R., McKinnon, P., Shadgan, B., \& Reid, W. D. (2009). The effects of eccentric versus concentric resistance training on muscle strength and mass in healthy adults: A systematic review with meta-analysis. British Journal of Sports Medicine, 43(8), 556-568. https://doi.org/10.1136/bjsm.2008.051417

Rose, J., \& Mcgill, K. (1998). The motor unit in cerebral palsy. Developmental Medicine \& Child Neurology, 40, 270-277. Retrieved from papers2://publication/uuid/B70Doo3F-9Fo4-4F96-9D2C-43A868021E6C

Ross, S. M., MacDonald, M., \& Bigouette, J. P. (2016). Effects of strength training on mobility in adults with cerebral palsy: A systematic review. Disability and Health Journal, 9(3), 375-384. https://doi.org/10.1016/j.dhjo.2016.04.005

Rouissi, M., Chtara, M., Berriri, A., Owen, A., \& Chamari, K. (2016). Asymmetry of the modified Illinois change of direction test impacts young elite soccer players' performance. Asian Journal of Sports Medicine, 7(2). https://doi.org/10.5812/asjsm.33598

Scholtes, V. A., Becher, J. G., Janssen-Potten, Y. J., Dekkers, H., Smallenbroek, L., \& Dallmeijer, A. J. (2012). Effectiveness of functional progressive resistance exercise training on walking ability in children with cerebral palsy: A randomized controlled trial. Research in Developmental Disabilities, 33(1), 181-188. https://doi.org/10.1016/j.ridd.2011.08.026

Scholtes, V. A., Dallmeijer, A. J., Rameckers, E. A., Verschuren, O., Tempelaars, E., Hensen, M., \& Becher, J. G. (2008). Lower limb strength training in children with cerebral palsy - a randomized controlled trial protocol for functional strength training based on progressive resistance exercise principles. BMC Pediatrics, 8(1), 41. https://doi.org/10.1186/1471-2431-8-41

Silva, J. R., Nassis, G. P., \& Rebelo, A. (2015). Strength training in soccer with a specific focus on highly trained players. Sports Medicine - Open, 1(1). https://doi.org/10.1186/s40798-015-0006-z

Steenbergen, B., \& van der Kamp, J. (2008). Attentional processes of high-skilled soccer players with congenital hemiparesis: differences related to the side of the hemispheric lesion. Motor Control, 12(1), 55-66. https://doi.org/10.1123/mcj.12.1.55

Van Biesen, D., \& Pineda, R. C. (2019). Balance and strength assessment of Special Olympics athletes: How feasible and reliable is the FUNfitness test battery? European Journal of Adapted Physical Activity, 12(1), 1-12. https://doi.org/10.5507/euj.2019.004 
Verschuren, O., Smorenburg, A. R. P., Luiking, Y., Bell, K., Barber, L., \& Peterson, M. D. (2018). Determinants of muscle preservation in individuals with cerebral palsy across the lifespan: a narrative review of the literature. Journal of Cachexia, Sarcopenia and Muscle, 9(3), 453-464. https://doi.org/10.1002/jcsm.12287

Weir, J. P., Housh, D. J., Housh, T. J., \& Weir, L. L. (1995). The effect of unilateral eccentric weight training and detraining on joint angle specificity, cross-training, and the bilateral deficit. Journal of Orthopaedic \& Sports Physical Therapy, 22(5), 207215. https://doi.org/10.2519/jospt.1995.22.5.207

Wirth, K., Keiner, M., Szilvas, E., Hartmann, H., \& Sander, A. (2015). Effects of eccentric strength training on different maximal strength and speed-strength parameters of the lower extremity. Journal of Strength and Conditioning Research, 29(7), 1837-1845. https://doi.org/10.1519/JSC.ooooooooooo00528

Yanci, J., Castagna, C., Los Arcos, A., Santalla, A., Grande, I., Figueroa, J., \& Camara, J. (2016). Muscle strength and anaerobic performance in football players with cerebral palsy. Disability and Health Journal, 9(2), 313-319. https://doi.org/10.1016/j.dhjo.2015.11.003

Yanci, J., Castillo, D., Iturricastillo, A., \& Reina, R. (2019). Evaluation of the official match external load in soccer players with cerebral palsy. Journal of Strength and Conditioning Research, 33(3), 866-873. https://doi.org/10.1519/JSC.0000000000002085

Yanci, J., Castillo, D., Iturricastillo, A., Urbán, T., \& Reina, R. (2018). External match loads of footballers with cerebral palsy: A comparison among sport classes. International Journal of Sports Physiology and Performance, 13(5), 590-596. https://doi.org/10.1123/ijspp.2017-0042

(C) 2020 by the authors. Submitted for possible open access publication under the terms and conditions of the Creative Commons Attribution (CC BY) license (http://creativecommons.org/licenses/by/4.o/). 